\title{
Does unilateral transtibial amputation lead to greater metabolic demand during walking?
}

\author{
Elizabeth Russell Esposito, PhD; ${ }^{1-2^{*}}$ Kelly M. Rodriguez, MS; ${ }^{1}$ Christopher A. Ràbago, PT, PhD; ${ }^{1-2}$ Jason M. \\ Wilken, PT, PhD ${ }^{1-2}$ \\ ${ }^{1}$ Center for the Intrepid, Department of Orthopaedics and Rehabilitation, Brooke Army Medical Center, Fort Sam \\ Houston, TX; ${ }^{2}$ Department of Defense-Department of Veterans Affairs Extremity Trauma and Amputation Center of \\ Excellence
}

\begin{abstract}
Previous literature reports greater metabolic demand of walking following transtibial amputation. However, most research focuses on relatively older, less active, and often dysvascular amputees. Servicemembers with traumatic amputation are typically young, fit, and highly active before and often following surgical amputation of their lower limb. This study compared the metabolic demand of walking in young, active individuals with traumatic unilateral transtibial amputation (TTA) and nondisabled controls. Heart rate (HR), rate of oxygen consumption, and rating of perceived exertion (RPE) were calculated as subjects walked at a self-selected velocity and at five standardized velocities based on leg length. The TTA group completed a Prosthetics Evaluation Questionnaire. Oxygen consumption ( $p=0.89)$, net oxygen consumption $(p=$ $0.32)$, and RPE $(p=0.14)$ did not differ between groups. Compared with controls, HR was greater in the TTA group and increased to a greater extent with velocity $(p<0.001)$. Overall, the TTA group rated their walking abilities as high (mean: 93\% out of $100 \%$ ). This is the first study to report equivalent metabolic demand between persons with amputation and controls walking at the same velocity. These results may reflect the physical fitness of the young servicemembers with traumatic amputations and may serve to guide outcome expectations in the future.
\end{abstract}

Key words: amputee, energetics, gait, heart rate, military, oxygen consumption, prosthetic, servicemember, speed, traumatic.

\section{INTRODUCTION}

It is widely accepted that individuals with a transtibial amputation (TTA) have greater metabolic demands during walking than nondisabled nonamputees. At similar walking speeds, metabolic demand for individuals with unilateral TTA is 9-33 percent greater [1-7] than nondisabled individuals and can influence rehabilitation, prosthetic prescription, and patient participation in daily physical activities. Those with TTA appear to compensate for the increase in energy expenditure by adopting self-selected walking speeds 7-42 percent slower than nondisabled individuals [4,8-9]. Walking slower allows them to achieve equivalent metabolic rates as nondisabled individuals $[2,10]$, potentially to limit physical exertion [6]. The end result, however, is a 14 percent greater total metabolic cost to walk an equivalent distance to nondisabled individuals [8].

Abbreviations: $\mathrm{AVO}_{2}=$ arterio-venous difference, $\mathrm{FR}=$ Froude, HR = heart rate, PEQ = Prosthetics Evaluation Questionnaire, RPE = rating of perceived exertion, SSWV $=$ selfselected walking velocity, TTA = transtibial amputation, $\mathrm{VO}_{2}=$ rate of oxygen consumption.

*Address all correspondence to Elizabeth Russell Esposito, PhD; 3551 Roger Brooke Dr, Center for the Intrepid, Fort Sam Houston, TX 78234; 210-539-5824.

Email: Erussell.kin@gmail.com

http://dx.doi.org/10.1682/JRRD.2014.06.0141 
Several biomechanical factors relating to the loss of the ankle plantar flexor musculature have been associated with the high metabolic demand of walking in individuals with TTA. Ankle plantar flexors are responsible for more than 80 percent of the mechanical power generated during push-off [11]. Although prosthetic technology has improved over the years, prosthetic feet are still largely passive in nature and, therefore, incapable of fully restoring lost power at push-off. The resulting gait is asymmetrical and requires additional muscle forces from the intact limb to compensate for deficiencies in the amputated limb [12]. Muscular compensations, such as isometric and/or antagonistic contractions, increase the metabolic cost of walking $[3,13]$. An individual's ability to reduce these compensations depends on a variety of factors that are not all biomechanical.

Abnormal kinematics and associated compensations may be overemphasized as the cause of the high metabolic demand in individuals with lower-limb amputations [14]. Other influencing factors include walking surface [6,8,15-16], prosthetic componentry [17-21], prosthesis gait experience [22], residual limb length [1,10], baseline fitness [1,6,23], age [1,6], and comorbidities [9,23]. Gaily et al. considered multiple factors of energy expenditure following TTA and found that the baseline rate of oxygen consumption $\left(\mathrm{VO}_{2}\right)$ contributed to 40 percent of the variance in the data [1]. Physical fitness is a large contributor to baseline $\mathrm{VO}_{2}$ and is, therefore, a primary factor affecting the metabolic demand of ambulation [1]. A 1979 report concluded that $\mathrm{VO}_{2}$ may be reasonably reduced with exercise in a population of individuals with unilateral TTA [17]. However, the vast majority of the participants in this study sustained amputation as the result of vascular pathologies. When assessing metabolic demand, individuals with traumatic, as opposed to dysvascular, amputation may represent a distinct subset.

In general, civilians with traumatic TTA incur lower metabolic cost per unit distance walked than dysvascular amputees [23]. Torburn et al. [23] found that individuals with traumatic TTA were of better physical fitness because their amputations were not due to medical conditions or behaviors that typically affect metabolic rate (e.g., diabetes, peripheral vascular disease, smoking [24]). In the military, a majority of amputations are traumatic in nature. The Active Duty servicemembers who sustain these injuries are typically at high levels of physical fitness before injury and undergo intensive rehabilitation following injury. As a result, common assumptions regarding the metabolic consequences of TTA may not apply to the servicemember with a traumatic amputation who is young and physically fit. Therefore, the purpose of this study was to compare metabolic demand between young, highly active individuals who had sustained traumatic unilateral TTA and nondisabled controls.

\section{METHODS}

Thirteen males with unilateral TTA and 13 nondisabled male subjects participated in this study. All subjects were servicemembers and amputations were the result of traumatic high-energy impacts or explosions. At the time of data collection, these individuals were in relatively early stages of recovery and prosthetic use. Other inclusion criteria consisted of 18-45 yr of age and independent ambulation with a passive, energy-storage-and-return prosthetic foot for at least 2 mo. Exclusion criteria consisted of conditions affecting metabolism and/or comorbidities that did not permit safe, independent ambulation. Nondisabled subjects with no current history of injuries or surgeries were recruited from the local population of Active Duty military personnel. Treadmill experience was not recorded as part of inclusion and exclusion criteria. All subjects provided written informed consent for the research procedures approved by the Brooke Army Medical Center Institutional Review Board.

Metabolic data were collected using a portable metabolic unit with $30 \mathrm{~s}$ averaging (K4b2, Cosmed, Inc; Rome, Italy) [25]. Subjects wore a heart rate (HR) monitor (Polar Electro Inc; Lake Success, New York) on their chest and a plastic metabolic mask secured over their nose and mouth. Ratings of perceived exertion (RPEs) were selected from a Borg 20-point scale [26] at the conclusion of each velocity condition. Walking took place on a treadmill without the use of upper-limb assistance at five standardized velocities and one self-selected walking velocity (SSWV). SSWV was based on the subject's preferred overground walking velocity averaged over 10 passes across a $10 \mathrm{~m}$ walkway. Standardized velocities were based on the length of the intact limb (measured from the greater trochanter to the floor) and were equal to Froude (FR) numbers of 0.06 (FR1), 0.10 (FR2), 0.16 (FR3), 0.23 (FR4), and 0.31 (FR5) using the following Equation [27]:

$$
\text { Velocity }=\sqrt{\text { FR } * \text { Gravity } * \text { Leg Length }} .
$$


FR numbers were used to scale walking velocities to leg length to facilitate equivalent task demands across individuals with different anthropometric characteristics. Previous experience with individuals with unilateral TTA indicates that FR3 is generally closest to the SSWV, and two slower and two faster velocities were selected to incorporate the range of achievable walking velocities for this patient population.

All testing was conducted in a single session. Subjects began testing by sitting quietly for $10 \mathrm{~min}$ to establish baseline resting $\mathrm{HR}$ and $\mathrm{VO}_{2}$ values. Subjects then walked, progressing from the slowest to the fastest velocity, for approximately $5 \mathrm{~min}$ at each velocity condition, or until steady-state oxygen consumption was achieved, and walked at steady state for at least $2 \mathrm{~min}$. Rest was given between conditions as needed. If rest was not needed, subjects continued through the progressive velocity protocol. In the final $30 \mathrm{~s}$ of each condition, subjects indicated their RPE. In addition, the TTA group completed a Prosthetic Evaluation Questionnaire (PEQ) [28] and specific questions related to walking ability, energetic cost, and pain were selected for analysis (questions presented in Figure 1).

Steady-state $\mathrm{VO}_{2}$ was averaged during the final 2 min of data collection and scaled to biological body mass. Net $\mathrm{VO}_{2}$ was calculated as baseline $\mathrm{VO}_{2}$ subtracted from steady state $\mathrm{VO}_{2}$ during walking. Because walking velocities were not different between groups, metabolic cost calculations were not necessary. RPE values were averaged across subjects within each group at each velocity and standard deviations were calculated. PEQ scores were evaluated by measuring the distance marked by the subject on a line. Mean values and standard deviations were recorded for each question.

Individuals with TTA were compared with controls using a repeated-measures analysis of variance (group $x$ velocity). Significant main effects of group were separated with post hoc, unpaired $t$-tests. Because the primary aim of the study was to compare between groups, between-speed comparisons were not performed post hoc. Linear regressions compared the dependent variables of $\mathrm{HR}$ and $\mathrm{VO}_{2}$ to RPE.

\section{RESULTS}

There were no significant demographic differences between groups (Table 1). Individuals with traumatic unilateral TTA and nondisabled controls did not differ in terms of age $(p=0.30)$, height $(p=0.74)$, mass ( $p=$ $0.11)$, leg length $(p=0.78)$, or SSWV ( $p=0.63)$. Of the 12 subjects in the TTA group who responded to all PEQ questions, 9 reported participating in physical therapy at the time of the metabolic testing. These 9 subjects spent an average of $2.6 \mathrm{~h} / \mathrm{d}$ and approximately $4.6 \mathrm{~d} /$ wk participating in therapy activities. Overall, the TTA group devoted an average of $11.5 \mathrm{~h} /$ wk to cardiovascular and/or strength training activity.

Table 2 presents $\mathrm{VO}_{2}, \mathrm{HR}$, and RPE at each of the five walking velocities. Gross metabolic rates were not different between the TTA and control groups at any velocity, but resting rates were lower in the TTA group $(p=0.049)$ (Figure 2(a)). Net $\mathrm{VO}_{2}$ was calculated for comparison (Figure 2(b)), but net rate also did not differ between the two groups at any velocity $(p=0.32)$. RPE was not significantly different between individuals with TTA and controls at any velocity $(p=0.14)$ (Figure 2(d)). HR was not significantly different between the groups at baseline ( $p=0.79$ ), but there was a significant interaction between group and speed $(p<0.001)$ such that HR was significantly greater in the TTA group across all walking conditions (main effect of group: $p=$ 0.002). Furthermore, HR in the TTA group increased to a greater extent with increasing walking velocity (main effect of speed: $p<0.001$ ) than did HR in the control group (Figure 2(c)). There were no other significant interactions.

Both groups experienced greater $\mathrm{VO}_{2}$ and indicated greater RPE as walking velocity increased from FR1 to FR5 ( $p<0.001$ for both dependent measures). Although subjects indicated higher levels of perceived exertion as both $\mathrm{VO}_{2}$ and $\mathrm{HR}$ increased, $\mathrm{VO}_{2}$ was more strongly correlated with RPE (control: $R^{2}=0.659$, TTA: $R^{2}=0.500$, Figure 3(a)) than HR (control: $R^{2}=0.295$, TTA: $R^{2}=$ 0.311 , Figure $3(\mathbf{b})$ ) in both groups.

Mean PEQ responses indicated that the individuals with unilateral TTA did not find walking with a prosthesis overly exhausting $(72 \%$ [100\% = not exhausting at all]), had high walking ability using their prosthesis (93\% $[100 \%=$ no problem walking with prosthesis]), and were satisfied with their walking ability (91\% [100\% = extremely satisfied]) (Figure 1). Out of the 13 TTA subjects, 12 indicated on the PEQ that they experienced some pain in their residual limb and 9 experienced some pain in their back. Pain levels were, on average, moderate to mild but were highly variable from subject to subject. 
JRRD, Volume 51, Number 8, 2014

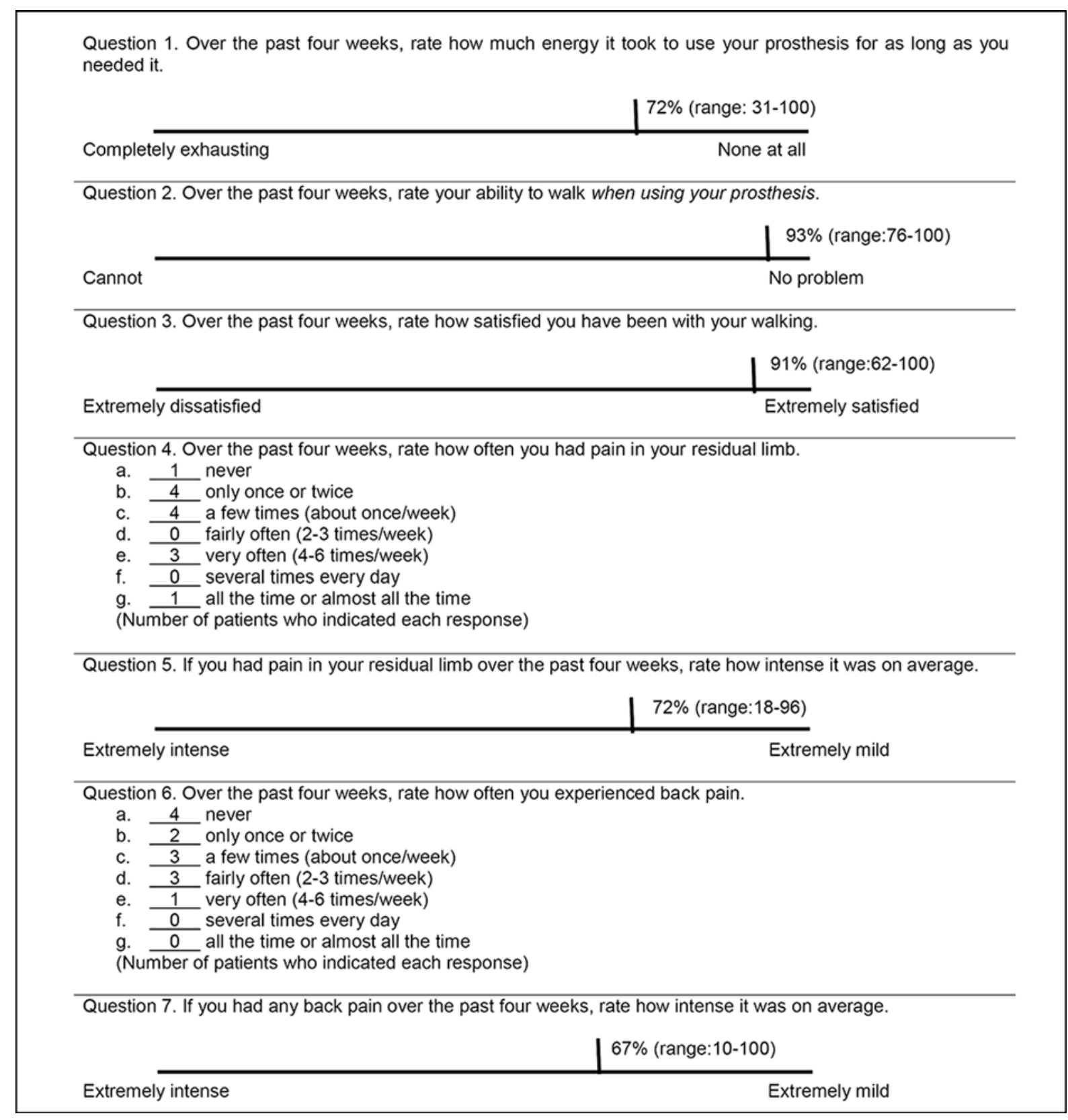

Figure 1.

Prosthetic Evaluation Questionnaire responses. Specific questions related to aims of this study were selected for analysis. Mean values are presented, where applicable, with a vertical line and range of responses.

\section{DISCUSSION}

The literature on individuals with amputations commonly reports greater metabolic demands of walking when compared with nondisabled individuals. However, study participants are often older, have amputations due to vascular issues, are less fit, and/or have been using prostheses for many years when compared with subjects in this present study. It was previously unknown how lower-limb amputation affected the metabolic demand of walking in young, active individuals with TTA across a range of walking velocities. In support of our hypothesis, 
Table 1.

Subject characteristics.

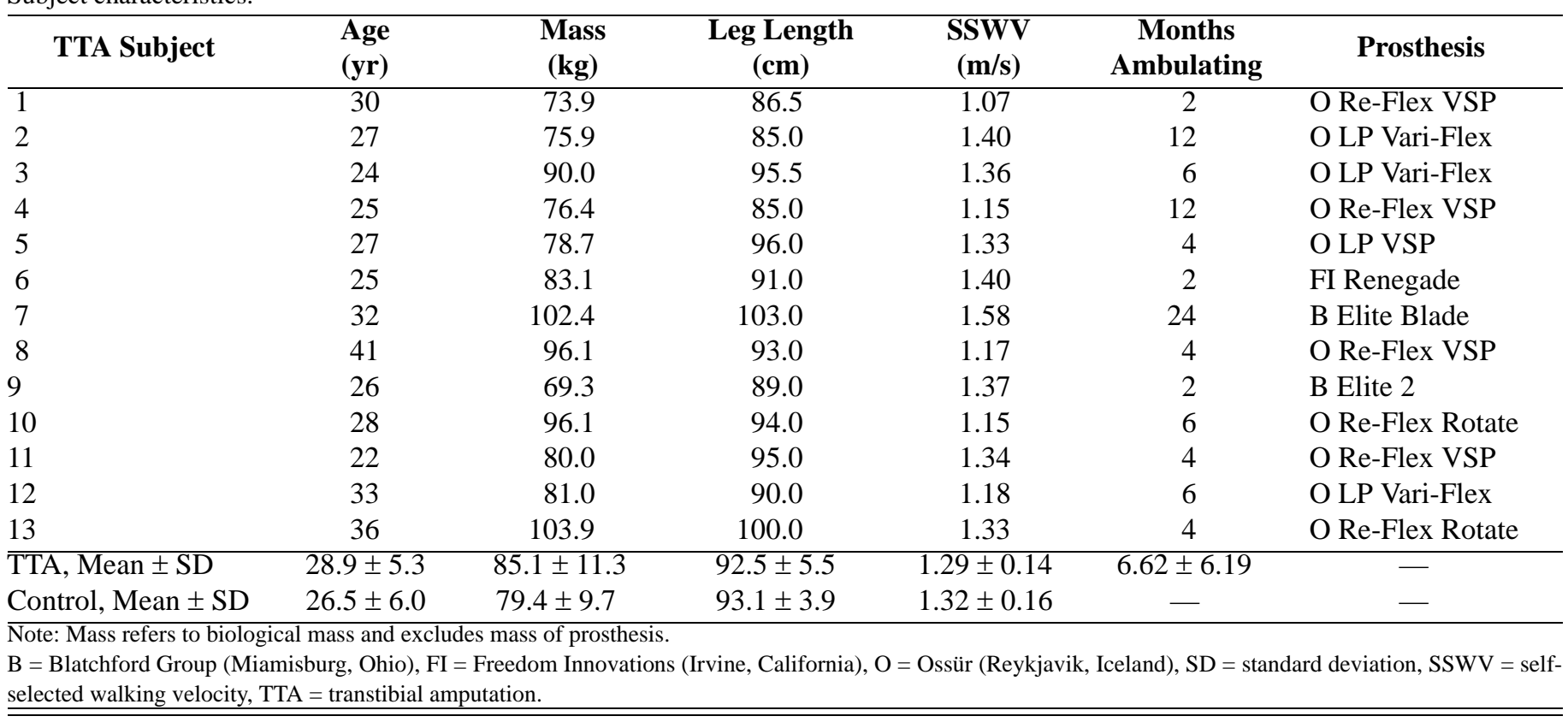

Table 2.

Mean \pm standard deviation dependent measures at each of five velocity conditions.

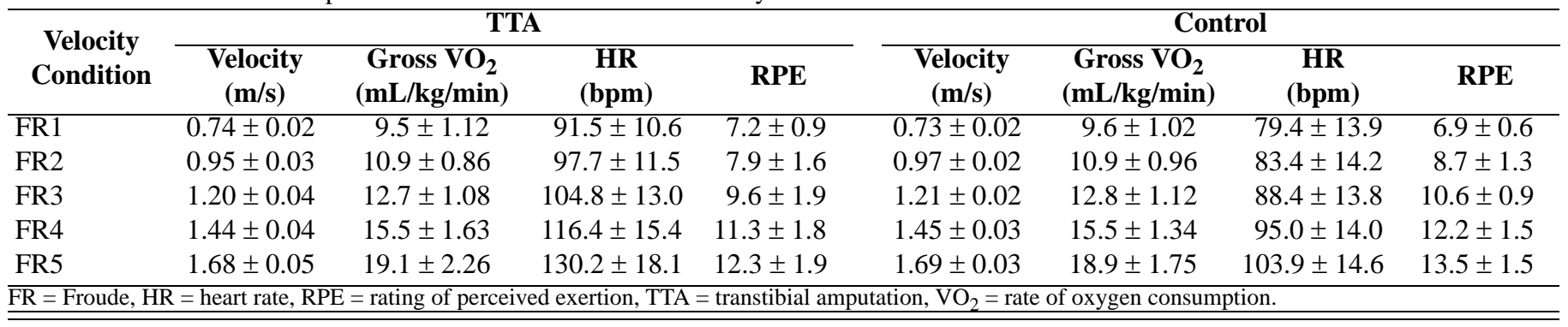

metabolic rate was not different between individuals with unilateral TTA and nondisabled controls across a range of walking velocities. Individuals with TTA also chose to walk at a SSWV that was equivalent to nondisabled. The only study that has reported equivalent metabolic demands between subjects with amputations and controls at similar speeds used powered prostheses with batterypowered push-off assistance to supplement lacking muscular efforts [18]. However, the present study is the first to report similar metabolic rates when using passive energy-storage-and-return prostheses and walking at equivalent speeds.

Metabolic rates for the individuals with traumatic TTA were substantially lower than those reported in the literature. Although walking velocities varied greatly across previous studies, when individuals with TTA walk at similar velocities to nondisabled controls, they typically have 9-33 percent greater metabolic demand [1$7,23]$. This increased metabolic rate was not observed at controlled or self-selected velocities in this study. To our knowledge, the only other reports of similar rates between individuals with amputation and nondisabled controls were the result of significantly slower walking velocities in the TTA group [15].

Walking economy is influenced by an individual's level of physical fitness $[1,6]$. Specifically, strength training and prosthetic training have both been found to decrease metabolic demand $[17,29]$. Therefore, it is suspected that these findings are due, at least in part, to the relatively high levels of physical fitness in both the TTA 

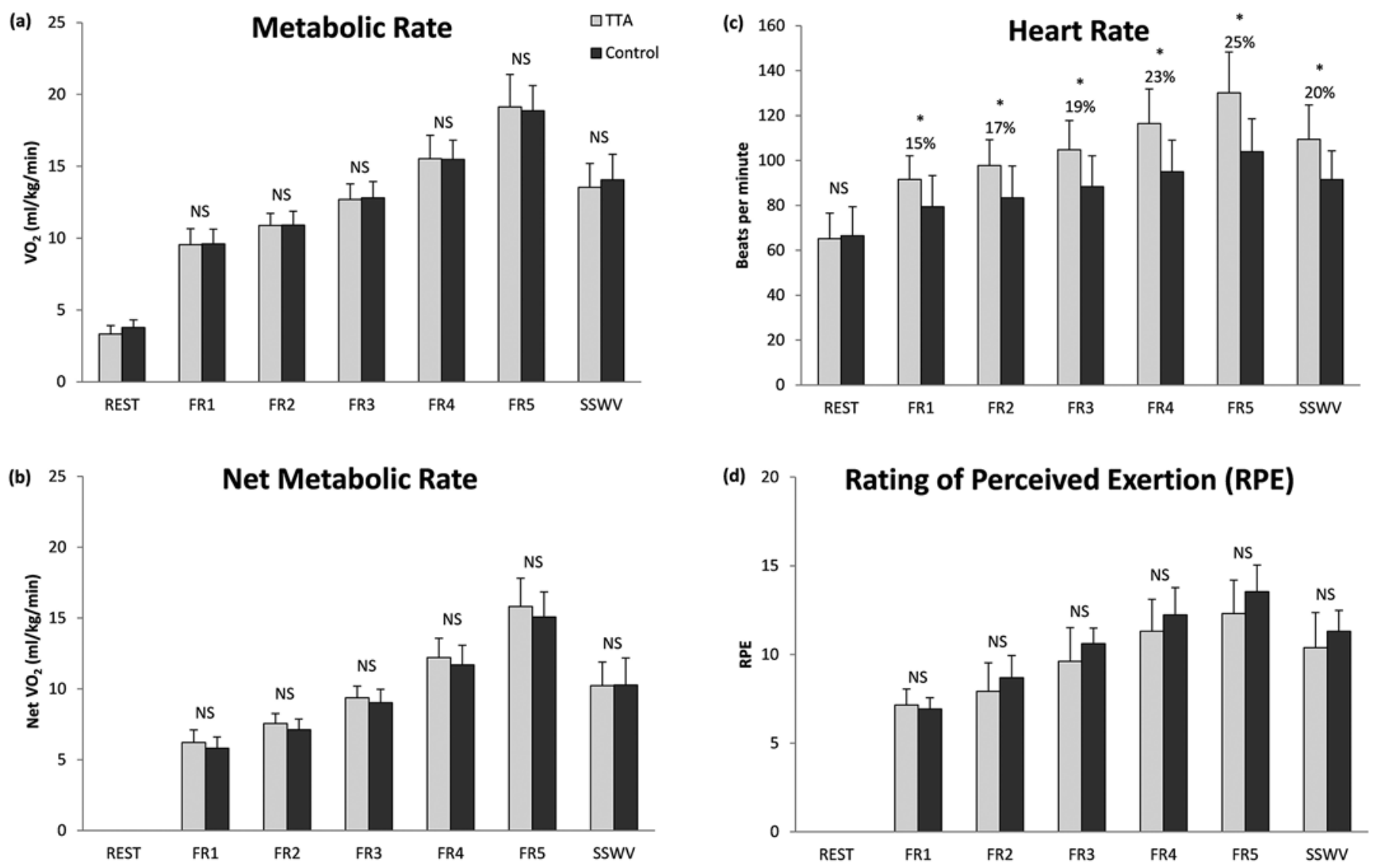

Figure 2.

Mean (standard deviation bars) dependent measures of (a) rate of oxygen consumption $\left(\mathrm{VO}_{2}\right)$, (b) net $\mathrm{VO}_{2}$, (c) heart rate, and (d) rating of perceived exertion (RPE) for subjects with transtibial amputation (TTA) and controls. * Statistically significant at $p<0.05$. Percent values indicate percent increase or decrease of TTA group from controls. FR = Froude, NS = not significant, SSWV = selfselected walking velocity.

and control groups comprised of young servicemembers. These results during the relatively low metabolic demand activity of walking may not carry over to high-intensity activities, such as running or load carriage, where the lack of lower-limb musculature may present a greater musculoskeletal and metabolic challenge. In fact, servicemembers with TTA do experience greater metabolic demands than controls during load carriage activities. In a similar patient population of young (26.9 yr), Active Duty servicemembers with TTA in early stages of rehabilitation, Schnall et al. found 9-11 percent greater $\mathrm{VO}_{2}$ in individuals with TTA than in controls when subjects were required to carry $32.7 \mathrm{~kg}$ loads [30]. The differences these authors found, however, were considerably less than previous reports comparing individuals with ampu- tations and nondisabled individuals, and RPE was not different between groups. Therefore, the results of Schnall et al. [30] combined with the results of the present study lend support to the notion that walking with a lower-limb prosthesis does not require a substantially greater metabolic cost when the user is young, active, and otherwise healthy. This specific population of young, active, and physically fit individuals with amputations is generally not found in the literature.

Individuals with TTA had lower baseline metabolic rates than controls. The lower resting $\mathrm{VO}_{2}$ suggests that the cardiovascular fitness levels may have been higher in the TTA group than in the control group. This present population was active and involved in rigorous rehabilitation. On average, subjects spent $11.5 \mathrm{~h} / \mathrm{wk}$ in cardiovascular and/or 

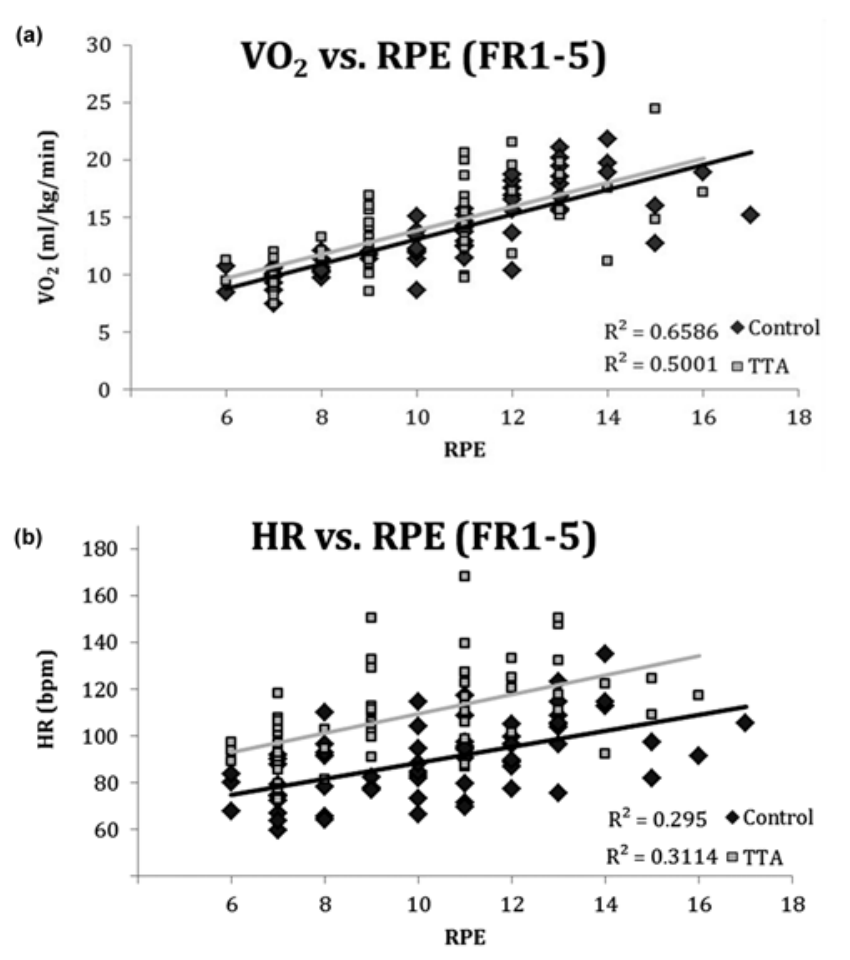

Figure 3.

(a) Rate of oxygen consumption $\left(\mathrm{VO}_{2}\right)$ and (b) heart rate $(\mathrm{HR})$ relative to rating of perceived exertion (RPE) with linear regression lines. Black regression lines correspond to control group and light gray regression lines correspond to transtibial amputation (TTA) group. Individual subject values are presented across all five walking speeds (Froude [FR] 1-5).

strength training and many performed a wide variety of high-intensity activities. Although previous research has reported a decline in physical activity postamputation [31], we expect this may not have been the case for the present subjects and that their physical fitness was the primary contributor to their lower resting $\mathrm{VO}_{2}$.

HR was also different between the two groups. Although equivalent $\mathrm{VO}_{2}$ values were observed between TTA and control groups during walking, HR was consistently greater in the TTA group. The greater HR measured in this population of individuals with unilateral TTA may indicate cardiac changes following amputation and warrant HR monitoring during exercise. HR, stroke volume, and the arterio-venous difference $\left(\mathrm{AVO}_{2}\right)$ are the three factors that determine $\mathrm{VO}_{2}$ [32]. Therefore, the greater $\mathrm{HR}$ in the TTA group necessitates that either stroke volume and/or $\mathrm{AVO}_{2}$ were lower than controls. It is possible that, despite their high levels of physical fitness, stroke volume decreased. Previous literature has shown that the contractile capacity of the myocardium decreases following major limb loss, regardless of the level or location of amputation [33]. Although it is unknown how these amputations directly affected $\mathrm{AVO}_{2}$, the acute disruption of the circulatory system due to amputation may also play a role in these results.

Overall, the lack of congruency between the HR and $\mathrm{VO}_{2}$ results was unexpected when comparing the two groups. At similar velocities to the present study, Gaily et al. [1] found an 18 percent greater $\mathrm{VO}_{2}$ and $\mathrm{HR}$ in TTA than in controls, while the present study found 20 percent greater HR, on average, across the five controlled speeds (larger differences with increasing walking velocities) with no difference in $\mathrm{VO}_{2}$. When comparing $\mathrm{VO}_{2}$ and $\mathrm{HR}, \mathrm{VO}_{2}$ was the stronger predictor of perceived exertion as walking velocity increased. However, previous work in a similar amputee population found that, when subjects were carrying a load, RPE was not strongly associated with $\mathrm{VO}_{2}$ [30]. At first glance, it may be suspected that a threshold exists at which individuals with amputation begin to experience greater metabolic demands of locomotion, such as when carrying heavy loads; however, the RPE values with load carriage fell within the range of those reported in the present study for similar metabolic demands. It is possible that the subjects in both Schnall et al. [30] and the present study may not have been sufficiently taxed during testing and the ranges of speeds and weights of loads were chosen because they were within the capabilities of the subject population. This speculation is supported in both studies by only moderate RPE values in the most physically demanding conditions tested and perceptions of exertion levels that were not different from nonamputees.

The present study is not the first to find similar performance between young, active servicemembers with TTA and nondisabled controls. There are several examples in which servicemembers who participated in intensive rehabilitation programs and had access to regular prosthetic care demonstrated smaller deficits than previously reported. For example, they have performed similarly to their nondisabled counterparts in areas such as activity performance, gait biomechanics, and walking stability [34-41]. It is important to recognize that the similarities observed here and elsewhere, while encouraging, do not represent an absence of dysfunction or the full restoration of function in all people or across all aspects of life. Other 
deficits are often still present requiring further rehabilitation to restore function and quality of life [42].

\section{LIMITATIONS}

This intensive rehabilitation and prosthetic care received by servicemembers with amputation may limit the generalizability of these results to the general population of people with amputation. In addition, comorbidities and concurrent injuries associated with traumatic limb loss can affect the homogeneity of the patient group and introduce a second study limitation. However, additional minor injuries are likely representative of the general population of individuals with traumatic lower-limb amputation. These additional injuries or comorbidities would be expected to result in greater gait deviations, which may then require greater oxygen consumption than nondisabled individuals. However, these differences were not found. Therefore, it was unlikely that any comorbidities influenced the results of this study or comparisons to the literature.

\section{CONCLUSIONS}

This is the first study to report equivalent metabolic rates between individuals with traumatic unilateral lowerlimb amputation and their nondisabled counterparts during walking at the same speed. These data collected from young, highly active individuals with traumatic lowerlimb amputation differ from the larger body of literature demonstrating greater rates in the older, relatively unfit, and/or dysvascular amputee. As new technology develops and powered devices that better emulate biological ankle function become mainstream options for individuals with TTA, the metabolic demands of locomotion are expected to decrease for all users. However, use of current energy-storage-and-return models may still be appropriately prescribed for the population addressed in the current study without the expectation of high metabolic demands.

\section{ACKNOWLEDGMENTS}

\section{Author Contributions:}

Study concept and design: E. Russell Esposito, J. M. Wilken.

Acquisition of data: K. M. Rodriguez.
Analysis and interpretation of data: E. Russell Esposito.

Statistical analysis: E. Russell Esposito.

Drafting of manuscript: E. Russell Esposito, K. M. Rodriguez, C. A. Ràbago.

Critical revision of manuscript for important intellectual content: E. Russell Esposito, K. M. Rodriguez, C. A. Ràbago, J. M. Wilken. Obtained funding: J. M. Wilken.

Financial Disclosures: The authors have declared that no competing interests exist.

Funding/Support: This material was based on work supported by the Telemedicine and Advanced Technology Research Center and the Military Amputee Research Program (contract W81XWH-06-20073).

Institutional Review: Subjects provided informed consent prior to participation. All procedures were approved by the Brooke Army Medical Center Institutional Review Board before study procedures were initiated.

Participant Follow-Up: The authors do not plan to directly inform study participants of the publication of this study.

Disclaimer: The views expressed herein are those of the authors and do not reflect the official policy or position of the Brooke Army Medical Center, the U.S. Army, the Department of Defense, or the U.S. Government.

\section{REFERENCES}

1. Gailey RS, Wenger MA, Raya M, Kirk N, Erbs K, Spyropoulos P, Nash MS. Energy expenditure of trans-tibial amputees during ambulation at self-selected pace. Prosthet Orthot Int. 1994;18(2):84-91. [PMID:7991365]

2. Ganguli S, Datta SR, Chatterjee BB, Roy BN. Performance evaluation of an amputee-prosthesis system in below-knee amputees. Ergonomics. 1973;16(6):797-810.

[PMID:4782575]

http://dx.doi.org/10.1080/00140137308924571

3. Genin JJ, Bastien GJ, Franck B, Detrembleur C, Willems PA. Effect of speed on the energy cost of walking in unilateral traumatic lower limb amputees. Eur J Appl Physiol. 2008;103(6):655-63. [PMID:18478251] http://dx.doi.org/10.1007/s00421-008-0764-0

4. Huang CT, Jackson JR, Moore NB, Fine PR, Kuhlemeier KV, Traugh GH, Saunders PT. Amputation: Energy cost of ambulation. Arch Phys Med Rehabil. 1979;60(1):18-24. [PMID:420566]

5. Molen NH. Energy-speed relation of below-knee amputees walking on a motor-driven treadmill. Int Z Angew Physiol. 1973;31(3):173-85. [PMID:4696826]

6. Waters RL, Mulroy S. The energy expenditure of normal and pathologic gait. Gait Posture. 1999;9(3):207-31. [PMID:10575082] http://dx.doi.org/10.1016/S0966-6362(99)00009-0

7. Hsu MJ, Nielsen DH, Lin-Chan SJ, Shurr D. The effects of prosthetic foot design on physiologic measurements, selfselected walking velocity, and physical activity in people 
with transtibial amputation. Arch Phys Med Rehabil. 2006; 87(1):123-29. [PMID:16401450]

http://dx.doi.org/10.1016/j.apmr.2005.07.310

8. Gailey RS, Nash MS, Atchley TA, Zilmer RM, Moline-Little GR, Morris-Cresswell N, Siebert LI. The effects of prosthesis mass on metabolic cost of ambulation in non-vascular transtibial amputees. Prosthet Orthot Int. 1997;21(1):9-16.

[PMID:9141121]

9. Pinzur MS, Gold J, Schwartz D, Gross N. Energy demands for walking in dysvascular amputees as related to the level of amputation. Orthopedics. 1992;15(9):1033-36, discussion 1036-37. [PMID:1437862]

10. Gonzalez EG, Corcoran PJ, Reyes RL. Energy expenditure in below-knee amputees: Correlation with stump length. Arch Phys Med Rehabil. 1974;55(3):111-19. [PMID:4817680]

11. Winter DA. Biomechanical motor patterns in normal walking. J Mot Behav. 1983;15(4):302-30. [PMID:15151864] http://dx.doi.org/10.1080/00222895.1983.10735302

12. Tesio L, Lanzi D, Detrembleur C. The 3-D motion of the centre of gravity of the human body during level walking. II. Lower limb amputees. Clin Biomech (Bristol, Avon). 1998;13(2):83-90. [PMID:11415775] http://dx.doi.org/10.1016/S0268-0033(97)00081-8

13. Kasch FW, Wallace JP, Vancamp SP, Verity L. A longitudinal study of cardiovascular stability in active men aged 45 to 65 years. Phys Sportsmed. 1988;16(1):117-26.

14. Gitter A, Czerniecki J, Weaver K. A reassessment of center-of-mass dynamics as a determinate of the metabolic inefficiency of above-knee amputee ambulation. Am J Phys Med Rehabil. 1995;74(5):332-38. [PMID:7576408] http://dx.doi.org/10.1097/00002060-199509000-00002

15. Paysant J, Beyaert C, Datié AM, Martinet N, André JM. Influence of terrain on metabolic and temporal gait characteristics of unilateral transtibial amputees. J Rehabil Res Dev. 2006;43(2):153-60. [PMID:16847782] http://dx.doi.org/10.1682/JRRD.2005.02.0043

16. Traballesi M, Porcacchia P, Averna T, Brunelli S. Energy cost of walking measurements in subjects with lower limb amputations: A comparison study between floor and treadmill test. Gait Posture. 2008;27(1):70-75. [PMID:17360186]

http://dx.doi.org/10.1016/j.gaitpost.2007.01.006

17. Cummings V, March H, Steve L, Robinson KG. Energy costs of below-knee prostheses using two types of suspension. Arch Phys Med Rehabil. 1979;60(7):293-97.

[PMID:454125]

18. Herr HM, Grabowski AM. Bionic ankle-foot prosthesis normalizes walking gait for persons with leg amputation. Proc Biol Sci. 2012;279(1728):457-64. [PMID:21752817] http://dx.doi.org/10.1098/rspb.2011.1194

19. Mattes SJ, Martin PE, Royer TD. Walking symmetry and energy cost in persons with unilateral transtibial amputa- tions: Matching prosthetic and intact limb inertial properties. Arch Phys Med Rehabil. 2000;81(5):561-68.

[PMID:10807092]

http://dx.doi.org/10.1016/S0003-9993(00)90035-2

20. Nielsen DH, Shurr DG, Golden JC, Meier K. Comparison of energy-cost and gait efficiency during ambulation in below-knee amputees using different prosthetic feet: A preliminary report. J Prosthet Orthot. 1988;1(1):24-31. http://dx.doi.org/10.1097/00008526-198810000-00006

21. Schmalz T, Blumentritt S, Jarasch R. Energy expenditure and biomechanical characteristics of lower limb amputee gait: The influence of prosthetic alignment and different prosthetic components. Gait Posture. 2002;16(3):255-63. [PMID:12443950] http://dx.doi.org/10.1016/S0966-6362(02)00008-5

22. Williamson VC. Amputation of the lower extremity: an overview. Orthop Nurs. 1992;11(2):55-65.

23. Torburn L, Powers CM, Guiterrez R, Perry J. Energy expenditure during ambulation in dysvascular and traumatic below-knee amputees: A comparison of five prosthetic feet. J Rehabil Res Dev. 1995;32(2):111-19.

[PMID:7562650]

24. Kulkarni J, Pande S, Morris J. Survival rates in dysvascular lower limb amputees. Int J Surg. 2006;4(4):217-21.

[PMID:17462354]

http://dx.doi.org/10.1016/j.ijsu.2006.06.027

25. Darter BJ, Rodriguez KM, Wilken JM. Test-retest reliability and minimum detectable change using the K4b2: Oxygen consumption, gait efficiency, and heart rate for healthy adults during submaximal walking. Res Q Exerc Sport. 2013;84(2):223-31. [PMID:23930548]

http://dx.doi.org/10.1080/02701367.2013.784720

26. Borg GA. Perceived exertion. Exerc Sport Sci Rev. 1974; 2:131-53. [PMID:4466663] http://dx.doi.org/10.1249/00003677-197400020-00006

27. Vaughan CL, O’Malley MJ. Froude and the contribution of naval architecture to our understanding of bipedal locomotion. Gait Posture. 2005;21(3):350-62. [PMID:15760752] http://dx.doi.org/10.1016/j.gaitpost.2004.01.011

28. Legro MW, Reiber GD, Smith DG, del Aguila M, Larsen J, Boone D. Prosthesis evaluation questionnaire for persons with lower limb amputations: Assessing prosthesis-related quality of life. Arch Phys Med Rehabil. 1998;79(8):931-38. [PMID:9710165] http://dx.doi.org/10.1016/S0003-9993(98)90090-9

29. Pitetti KH, Snell PG, Stray-Gundersen J, Gottschalk FA. Aerobic training exercises for individuals who had amputation of the lower limb. J Bone Joint Surg Am. 1987;69(6): 914-21. [PMID:3597505]

30. Schnall BL, Wolf EJ, Bell JC, Gambel J, Bensel CK. Metabolic analysis of male servicemembers with transtibial amputations carrying military loads. J Rehabil Res Dev. 
JRRD, Volume 51, Number 8, 2014

2012;49(4):535-44. [PMID:22773257]

http://dx.doi.org/10.1682/JRRD.2011.04.0075

31. Bussmann JB, Schrauwen HJ, Stam HJ. Daily physical activity and heart rate response in people with a unilateral traumatic transtibial amputation. Arch Phys Med Rehabil. 2008;89(3):430-34. [PMID:18295619] http://dx.doi.org/10.1016/j.apmr.2007.11.012

32. Fick A. Uber die messung des blutquantums in den hertzvent rikeln. Sitzber Physik-Med Ges Wurzburg. 1870;36. German.

33. Kurdibaylo SF. Obesity and metabolic disorders in adults with lower limb amputation. J Rehabil Res Dev. 1996;33(4): 387-94. [PMID:8895133]

34. Beurskens R, Wilken JM, Dingwell JB. Dynamic stability of individuals with transtibial amputation walking in destabilizing environments. J Biomech. 2014;47(7):1675-81.

[PMID:24679710] http://dx.doi.org/10.1016/j.jbiomech.2014.02.033

35. Beltran EJ, Dingwell JB, Wilken JM. Margins of stability in young adults with traumatic transtibial amputation walking in destabilizing environments. J Biomech. 2014;47(5): 1138-43. [PMID:24444777] http://dx.doi.org/10.1016/j.jbiomech.2013.12.011

36. Gates DH, Darter BJ, Dingwell JB, Wilken JM. Comparison of walking overground and in a Computer Assisted Rehabilitation Environment (CAREN) in individuals with and without transtibial amputation. J Neuroeng Rehabil. 2012;9:81. [PMID:23150903] http://dx.doi.org/10.1186/1743-0003-9-81

37. Gates DH, Dingwell JB, Scott SJ, Sinitski EH, Wilken JM. Gait characteristics of individuals with transtibial amputations walking on a destabilizing rock surface. Gait Posture. 2012;36(1):33-39. [PMID:22469772] http://dx.doi.org/10.1016/j.gaitpost.2011.12.019

38. Gailey RS, Scoville C, Gaunaurd IA, Raya MA, Linberg AA, Stoneman PD, Campbell SM, Roach KE. Construct validity of Comprehensive High-Level Activity Mobility Predictor (CHAMP) for male servicemembers with traumatic lowerlimb loss. J Rehabil Res Dev. 2013;50(7):919-30.

[PMID:24301429]

http://dx.doi.org/10.1682/JRRD.2012.05.0100
39. Gates DH, Scott SJ, Wilken JM, Dingwell JB. Frontal plane dynamic margins of stability in individuals with and without transtibial amputation walking on a loose rock surface. Gait Posture. 2013;38(4):570-75. [PMID:23481866] http://dx.doi.org/10.1016/j.gaitpost.2013.01.024

40. Ferris AE, Aldridge JM, Rábago CA, Wilken JM. Evaluation of a powered ankle-foot prosthetic system during walking. Arch Phys Med Rehabil. 2012;93(11):1911-18. [PMID:22732369] http://dx.doi.org/10.1016/j.apmr.2012.06.009

41. Sinitski EH, Hansen AH, Wilken JM. Biomechanics of the ankle-foot system during stair ambulation: Implications for design of advanced ankle-foot prostheses. J Biomech. 2012; 45(3):588-94. [PMID:22177669]

http://dx.doi.org/10.1016/j.jbiomech.2011.11.007

42. Doukas WC, Hayda RA, Frisch HM, Andersen RC, Mazurek MT, Ficke JR, Keeling JJ, Pasquina PF, Wain HJ, Carlini AR, MacKenzie EJ. The Military Extremity Trauma Amputation/Limb Salvage (METALS) study: Outcomes of amputation versus limb salvage following major lower-extremity trauma. J Bone Joint Surg Am. 2013;95(2):138-45.

[PMID:23324961]

http://dx.doi.org/10.2106/JBJS.K.00734

Submitted for publication June 2, 2014. Accepted in revised form August 29, 2014.

This article and any supplementary material should be cited as:

Russell Esposito E, Rodriguez KM, Ràbago CA, Wilken JM. Does unilateral transtibial amputation lead to greater metabolic demand during walking? J Rehabil Res Dev. 2014;51(8):1287-96.

http://dx.doi.org/10.1682/JRRD.2014.06.0141

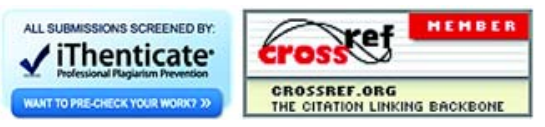

